\title{
A randomized, double-blind study comparing the effects of beclomethasone and fluticasone on bone density over two years
}

\author{
J.J. Egan*, C. Maden**, S. Kalra*, J.E. Adams ${ }^{+}$, R. Eastell ${ }^{\#}$, A.A. Woodcock*
}

A randomized, double-blind study comparing the effects of beclomethasone and fluticasone on bone density over two years. J.J. Egan, C. Maden, S. Kalra, J.E. Adams, R. Eastell, A.A. Woodcock. (C) ERS Journals Ltd 1999.

ABSTRACT: Cross-sectional studies have suggested that asthmatic patients receiving high dose inhaled corticosteroids and intermittent courses of oral corticosteroids have reduced bone mass. This prospective 2 -yr study was undertaken to evaluate changes in bone density of patients receiving high doses of inhaled corticosteroids.

Patients (n=33) (males aged 18-50 yrs, females aged 18-40 yrs) on inhaled corticosteroids $1,000-2,000 \mu \mathrm{g} \cdot \mathrm{day}^{-1}$, were randomized in a double-blind fashion to either fluticasone propionate (FP) $1,000 \mu \mathrm{g} \cdot \mathrm{day}^{-1}$ or beclomethasone dipropionate (BDP) 2,000 $\mu \mathrm{g} \cdot \mathrm{day}^{-1}$. In parallel, three open control groups of the same age range were studied: asthmatics $(\mathrm{n}=8)$ receiving low dose inhaled corticosteroids $\left(\leq 400 \mu \mathrm{g} \cdot \mathrm{day}^{-1}\right)$ (group A); chronic, severe asthmatics $(n=8)$ receiving oral corticosteroids $\left(\geq 10 \mathrm{mg}^{-d_{a y}}{ }^{-1}\right)$ (group B); and healthy untreated volunteers $(n=7)$ (group $C)$. Bone densitometry scans (quantitative computed tomography (QCT) of spine; dual X-ray absorptiometry of spine, femoral neck, and single photon absorptiometry of forearm) were performed at baseline and after 6,12 and 24 months of treatment. Biochemical bone marker measurements (serum osteocalcin, bone alkaline phosphatase, pro-collagen type 1 carboxy terminal propeptide, deoxypyridinoline and C-telopeptide of type 1 collagen) were collected every 3 months.

Fifteen FP (mean age 36 yrs, six male) and 9 BDP patients (mean age 33 yrs, five male); completed the study. At 0 months, mean bone mineral density (BMD) was lower in patients receiving inhaled corticosteroids (both low dose and high dose) than in normal volunteers. In the FP-treated group, mean vertebral trabecular BMD quantitative computed tomography remained stable with no evidence of decline, whereas there was some decline in the BDP-treated group. The treatment difference between FP and BDP was statistically significant in favour of FP for quantitative computed tomography measurements after 12 months $(p=0.006)$ and 24 months $(p=$ 0.004).

This study suggests that over 24 months, changes in bone density are minimal in patients on high-dose inhaled corticosteroids.

Eur Respir J 1999; 13: 1267-1275.

The optimal therapy for the management of asthma is anti-inflammatory medication in the form of corticosteroids and $\beta$-agonists. With the expanding use of topical inhaled corticosteroids, concern has been expressed about their long-term effects on extrapulmonary tissues [1]. Shortterm studies in normal subjects suggest that high-dose inhaled corticosteroids, particularly beclomethasone dipropionate (BDP) may affect bone metabolism adversely by lowering serum osteocalcin [2-4]. Case-control studies further suggest that patients receiving high-dose inhaled corticosteroids and intermittent courses of oral corticosteroids have reduced bone mass in comparison to controls $[5,6]$. These studies have raised a number of important questions. Firstly, what do the short-term changes in bone metabolism mean with respect to the long-term status of bone density in asthmatic patients? Secondly, what is the actual long-term influence of high doses of inhaled corticosteroids on bone density studied longitudinally?

\begin{abstract}
* North-West Lung Centre, Wythenshawe Hospital, Manchester, UK. ** GlaxoWellcome Research and Development, Greenford, Middlesex, UK. ${ }^{+}$Dept of Diagnostic Radiology, University of Manchester, Manchester, UK. " Dept of Human Metabolism and Clinical Biochemistry University of Sheffield, Sheffield, UK.
\end{abstract}

Correspondence: J. Egan

North West Lung Centre

Wythenshawe Hospital

Southmoor Road

Manchester M23 9LT

UK

Fax: 441612915054

Keywords: Asthma

bone density

inhaled corticosteroid

Received: June 51998

Accepted after revision December 261998

This study was funded by Glaxo Wellcome Research and Development. J.J. Egan was supported by the Lancactdis Foundation. Support for dual-energy Xray absorptiometry was also provided by the North-West Regional Health Authority Research Committee.
This double-blind, randomized study was undertaken to compare the effects of two long term ( 2 yrs) high-dose inhaled corticosteroids at equipotent doses, 1,000 $\mu \mathrm{g} \cdot$ day $^{-1}$ fluticasone proprionate (FP) and 2,000 $\mu \mathrm{g} \cdot \mathrm{day}^{-1} \mathrm{BDP}$, on the bone density and bone metabolism of a specific age range of patients with moderate to severe asthma.

\section{Methods}

\section{Patients}

Thirty-seven outpatients with chronic moderate to severe asthma, aged 18-50 yrs (males) or 18-40 yrs (females) were recruited into the double-blind study, 33 of whom were randomized to treatment, 17 to FP (mean age $36 \mathrm{yrs}$; seven male) and 16 to BDP (mean age 33 yrs; nine male). Their characteristics are summarized in table 1. All patients had been receiving regular treatment with BDP 
Table 1. - Patient demography and corticosteroid history

\begin{tabular}{|c|c|c|c|c|c|}
\hline & \multirow[b]{2}{*}{ 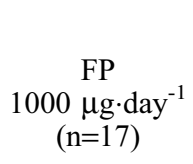 } & \multirow[b]{2}{*}{$\begin{array}{c}\text { BDP } \\
2000 \mu \mathrm{g} \cdot \mathrm{day}^{-1} \\
(\mathrm{n}=16)\end{array}$} & \multicolumn{3}{|c|}{ Open control groups } \\
\hline & & & $\underset{\substack{\text { Low dose inhaled CS } \\
(\mathrm{n}=16)}}{\mathrm{A}}$ & $\begin{array}{c}\text { B } \\
\text { Oral CS } \\
(\mathrm{n}=8)\end{array}$ & $\begin{array}{c}\mathrm{C} \\
\text { Healthy volunteers } \\
(\mathrm{n}=7)\end{array}$ \\
\hline Male/female & $7 / 10$ & $9 / 7$ & $8 / 8$ & $5 / 3$ & $4 / 3$ \\
\hline Mean age yrs & $36(8)$ & $33(10)$ & $30(7)$ & $42(6)$ & $32(4)$ \\
\hline Range yrs & $20-48$ & $20-50$ & $20-47$ & $35-51$ & $23-35$ \\
\hline Mean weight $\mathrm{kg}$ & $73(18)$ & $73(18)$ & $77(14)$ & $69(9)$ & $68(12)$ \\
\hline \multicolumn{6}{|l|}{ Duration of asthma $n$} \\
\hline$<10 \mathrm{yrs}$ & 5 & 4 & 9 & 1 & - \\
\hline$>10 \mathrm{yrs}$ & 12 & 12 & 7 & 7 & - \\
\hline \multicolumn{6}{|l|}{ History of atopy } \\
\hline Yes & 13 & 14 & 12 & 3 & - \\
\hline No & 4 & 2 & 4 & 5 & - \\
\hline Smoker $\mathrm{n}$ & 0 & 2 & 3 & 1 & 1 \\
\hline Exsmoker $\mathrm{n}$ & 7 & 2 & 5 & 4 & 1 \\
\hline Nonsmoker $\mathrm{n}$ & 10 & 9 & 8 & 3 & 5 \\
\hline PEFR L. $\min ^{-1}$ & $429(102.5)$ & 459 (135.9) & 489 (109.4) & $287(134.6)$ & - \\
\hline FEV1 L & $2.91(0.7)$ & $3.13(1.1)$ & $3.38(0.6)$ & $1.46(1.3)$ & - \\
\hline FVC L & $3.85(0.8)$ & $4.16(1.3)$ & $4.42(0.8)$ & $2.60(1.7)$ & - \\
\hline Mean dose inhaled CS at entry $\mu \mathrm{g} \cdot$ day $^{-1}$ & 1482 & 1293 & 350 & - & - \\
\hline \multicolumn{6}{|l|}{ Mean duration CS } \\
\hline Yrs & $5.0 \mathrm{inh}$ & $5.3 \mathrm{inh}$ & $3.25 \mathrm{inh}$ & 9.0 oral & - \\
\hline Range yrs & $0.25-18$ & $0.2-20$ & $0.1-15$ & $0.2-20$ & \\
\hline \multicolumn{6}{|l|}{ Mean duration oral CS } \\
\hline In last year weeks & 2.4 & 1.8 & - & 46.8 & \\
\hline Range weeks & $0-16$ & $0-7$ & & $10-52$ & \\
\hline
\end{tabular}

Data presented as numbers where shown, or mean (SD). FP: fluticasone propionate; BDP: beclomethasone dipropionate; PEFR: peak expiratory flow rate; FEV1: forced expiratory volume in one second; FVC: forced vital capacity; inh: inhalational; CS: corticosteroid.

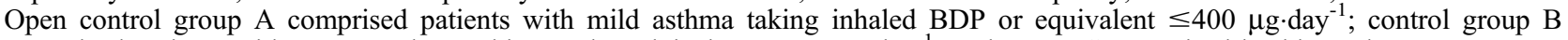
comprised patients with severe asthma taking oral prednisolone $\geq 10 \mathrm{mg} \cdot \mathrm{day}^{-1}$; and group $\mathrm{C}$ comprised healthy volunteers.

or budesonide at a dose of $1,000-2,000 \mu \mathrm{g} \cdot \mathrm{day}^{-1}$ for a mean of 5 yrs (FP group) or 5.3 yrs (BDP group). No patient had any changes in asthma medication in the 8 weeks prior to the study and no patient was receiving regular nasal corticosteroid therapy. Twelve patients in the FP group and 10 in the BDP group had received up to two courses of oral corticosteroids in the last year, although no patient had taken any oral corticosteroids in the last 8 weeks. All females were premenopausal and had regular menstrual cycles.

Three open control groups of subjects, within the same age-range as the double-blind treatment groups, were also studied: (control group A) comprised eight mild asthmatics (mean age 30 yrs; four male) who were receiving low doses of BDP or budesonide $\left(\leq 400 \mu \mathrm{g} \cdot\right.$ day $\left.^{-1}\right)$; (control group B) comprised eight chronic, severe asthmatics (mean age $42 \mathrm{yrs}$; five male) who were receiving maintenance oral prednisolone ( $\geq 10 \mathrm{mg}$ daily) and high dose inhaled corticosteroids (mean 1,500 $\mu \mathrm{g} \cdot \mathrm{day}^{-1}$ ); (control group C) comprised seven healthy untreated volunteers (mean age $32 \mathrm{yr}$; four male). Their characteristics are summarized in table 1 .

Ethical approval was obtained from South Manchester Trust Hospitals Ethical Committee and all subjects gave their written informed consent to participate in the study.

\section{Protocol}

The comparison of FP and BDP was a double-blind, randomized parallel group study with a treatment duration of 2 yrs preceded by a 2 -week run-in period. Clinic visits for assessment took place at the start of the run-in and then every 3 months. Patients who satisfied the entry criteria were randomized to receive either FP $500 \mu \mathrm{g}$ b.i.d. or BDP $1,000 \mu \mathrm{g}$ b.i.d. via metered dose inhaler (MDI) using a Volumatic ${ }^{\mathrm{TM}}$ spacer device. All patients were instructed to perform a throat gargle following inhalation. Asthma exacerbations could be treated with oral corticosteroids up to a maximum of two courses per year, but if this number was exceeded the patient was withdrawn. Other asthma medications were permitted (except for other inhaled corticosteroids, short-acting $\beta_{2}$-agonists other than salbutamol, and methylxanthines). Topical dermatological corticosteroids, intranasal corticosteroids for rhinitis, oral contraceptives, and calcium supplements were permitted. However, bone therapies including hormone replacement therapy, calcitonin and bisphosphonates were not permitted. Bone mineral density (BMD) measurements were performed at $0,6,12$ and 24 months and bone markers every 3 months.

The three open control groups were followed over the 2yr period. Control group A remained on their existing asthma maintenance treatment of $\leq 400 \mu \mathrm{g} \cdot \mathrm{day}^{-1} \mathrm{BDP}$ or budesonide and control group $\mathrm{B}$ remained on maintenance oral corticosteroids $\left(\geq 10 \mathrm{mg} \cdot\right.$ day $\left.^{-1}\right)$ and high dose inhaled corticosteroids at doses required for asthma control.

\section{Bone densitometry}

Quantitative computed tomography (QCT). Measurement of vertebral trabecular BMD at T12 to L3 was performed on a GE9800 general purpose scanner (General Electric, 
Milwaukee, WI, USA) using both single energy (SE) and dual energy (DE) low-dose scanning techniques and a liquid dipotassium hydrogen phosphate $\left(\mathrm{K}_{2} \mathrm{HPO}_{4}\right)$ calibration phantom [7]. Mean trabecular BMD was measured in grams per $\mathrm{cm}^{3}$ mineral equivalents of $\mathrm{K}_{2} \mathrm{HPO}_{4}$ in water. The precision of the SE-QCT technique is $1 \%$ in normal subjects (as in the present study) and 2.5\% in osteoporotic patients $[7,8]$. DE-QCT is used to correct for the negative effect of marrow fat on the estimation of trabecular BMD by SE-QCT, but has a poorer precision than the latter technique $[9,10]$. Baseline QCT values were also expressed as Z-scores. These represent the number of standard deviations above or below the statistical mean of a reference population, taking into account age and sex.

Dual energy X-ray absorptiometry (DXA). Measurement of integral bone was made of the lumbar spine (L2-L4), the right femoral neck and the whole body using a Lunar DPX-L scanner (Lunar Corporation, Madison, WI, USA) [11]. Mean BMD was measured in $\mathrm{g} \cdot \mathrm{cm}^{-2}$. Precision of the measurement is $1 \%$ in the spine, $2.5 \%$ in the femoral neck and $1 \%$ in the whole body.

Single photon absorptiometry (SPA). Bone mineral meassurement was performed by SPA using a Nuclear Data ND1100A scanner with a ${ }^{125} \mathrm{I}$ radionuclide source [12]. Scanning was performed at two sites: proximal and ultradistal. Bone mineral content (BMC) was measured in $\mathrm{g} \cdot \mathrm{cm}^{-1}$. Bone width (BW) was used to provide a measure of $\mathrm{BMD}(\mathrm{BMC} / \mathrm{BW})$ in $\mathrm{g} \cdot \mathrm{cm}^{-2}$. Precision of BMD measurement by SPA is $1 \%$ at the proximal site and $2 \%$ at the ultradistal site.

\section{Markers of bone turnover}

At each visit, a venous blood sample was taken and a urine sample collected during the first $2 \mathrm{~h}$ after initial voiding. All samples were collected between 08:00 and $10: 00 \mathrm{~h}$ and the serum stored at $-70^{\circ} \mathrm{C}$ for later batch measurement of bone formation markers, including osteocalcin (OC), bone alkaline phosphatase (BAP) and procollagen type 1 carboxyterminal propeptide (P1CP). Serum OC was measured using a commercial immunoradiometric kit (ELSA-OSTEO, CIS, Gif-sur-Yvette, France) with an intra-assay coefficient of variation $(\mathrm{CV})$ of $3 \%$. BAP was measured using the wheatgerm lectin precipitation method with an intra-assay CV of $6 \%$ [13]. P1CP was measured using a radioimmunoassay kit (Orion Diagnostica, Espoo, Finland) with an intra-assay $\mathrm{CV}$ of $6 \%$. In addition, parathyroid hormone (PTH) was measured by immunoradiometric assay (Nichols Institute, San Juan, CA, USA) with an intra-assay $\mathrm{CV}$ of $4 \%$. Urinary carboxyterminal cross-linked telepeptide (CTx) was measured by enzyme-linked immunosorbent assay (ELISA) using the Crosslaps kit (Osteometer Biotech A/S, Herlev, Denmark) with an intra-assay $\mathrm{CV}$ of $6 \%$. Free deoxypyridinoline (DPD) was measured by ELISA using the Pyrilinks D kit (Metra Biosystems, Palo Alto, CA, USA) with an intraassay $\mathrm{CV}$ of $5 \%$. In addition, urinary calcium was measured by atomic absorption spectrometry and urinary creatinine by Jaffé reaction. Values for urinary CTx and DPD were standardized to the creatinine concentration of the sample and expressed as a ratio per mmol creatinine.

\section{Clinical assessments}

Lung function measurements were performed at baseline and each 3 month clinic visit.

\section{Statistical analysis}

Absolute BMD values were the primary variables. The treatment differences between FP and BDP at 12 and 24 months were tested using analyses of covariance (ANCOVA), the model including terms for sex, age and baseline values. Analysis was by intention-to-treat and all patients' data were included where there was both a baseline and a 12 or a 24 month measurement. Serum cortisol data were log-transformed and then analysed as for bone density. Biochemical bone markers were analysed using nonparametric methods; frequency distributions were calculated and the Wilcoxon rank-sum test used to assess treatment differences between FP and BDP at 12 and 24 months. All statistical tests performed were two-sided, with p-values of $<0.05$ considered significant, and the $95 \%$ confidence intervals were calculated. No adjustment to the p-values was performed to take into account multiple significance testing. The double-blind study aimed to obtain evaluable data on 24 randomized patients at the end of 2 yrs. In the absence of data on which to base a power calculation at the time the study was initiated, this number of patients was based upon practical considerations. The data from control groups $\mathrm{A}, \mathrm{B}$ and $\mathrm{C}$ were tabulated using summary statistics, but no formal statistical analyses were performed.

\section{Results}

Thirty-seven patients were recruited to the double-blind study, four of whom withdrew before randomization (two failed to return, one was receiving testosterone therapy and one had Kallman's syndrome). Thirty-three patients were randomized to treatment (17 to FP and 16 to BDP). Overall, the two treatment groups were well matched with respect to demographic characteristics and corticosteroid history (table 1). Two patients withdrew from the FP group before completing 2 yrs of treatment: one owing to noncompliance and the other for social reasons. Seven patients withdrew from the BDP group: one because of an adverse event (low serum cortisol), three because of asthma exacerbation and three were noncompliant or did not return for clinic visits. A total of $15 \mathrm{FP}$ patients and 9 BDP completed the 2 yrs.

Sixteen patients were recruited into control group A, eight of whom withdrew before completing 2 yrs: one because of work commitments, another had a slipped disc, two became pregnant and four did not return for clinic visits. Eight patients were recruited into control group B and seven healthy volunteer subjects into control group $\mathrm{C}$, all of whom completed the $2 \mathrm{yr}$ study (table 1).

\section{Done densitometry}

Quantitative computed tomography. SE-QCT results for the individuals within each group on entry to the study are presented as Z-scores in figure 1. Six patients 


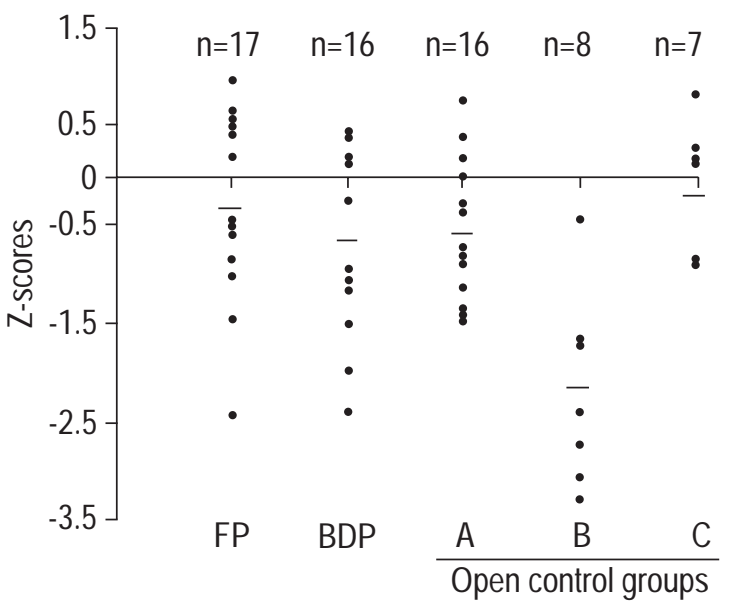

Fig. 1. - Absolute values (•) for each individual and the mean values for each group ( - , of single energy quantitative computed tomography Z-scores at entry into the study. FP: fluticasone propionate 1,000 $\mu \mathrm{g} \cdot$ day $^{-1}$; BDP: beclomethasone dipropionate $2,000 \mu \mathrm{g} \cdot$ day $^{-1}$; A: control group A, low-dose inhaled corticosteroids $\left(\leq 400 \mu \mathrm{g} \cdot\right.$ day $\left.^{-1}\right)$; B: control group $\mathrm{B}$, patients receiving maintenance oral corticosteroids $(\geq 10$ $\left.\mu \mathrm{g} \cdot \mathrm{day}^{-1}\right) ; \mathrm{C}$ : control group $\mathrm{C}$, normal volunteers.

at entry had a Z-score below the normal range $(<-2)$ including four of the eight control group B (oral corticosteroid), one in the FP group and one in the BDP group. The mean Z-scores were: -0.31 in the FP group, -0.61 in the BDP group, -0.56 in control group A (low-dose inhaled corticosteroids), -2.08 in control group B (oral corticosteroid) and -0.15 in control group $\mathrm{C}$ (volunteers).

In the FP group at baseline, the mean BMD with SEQCT was $152 \mathrm{mg} \cdot \mathrm{cm}^{-3}$ and this remained unchanged after 12 and 24 months of treatment $\left(154 \mathrm{mg} \cdot \mathrm{cm}^{-3}\right.$ and 153 $\mathrm{mg} \cdot \mathrm{cm}^{-3}$, respectively). In the BDP group, the baseline mean value of $152 \mathrm{mg} \cdot \mathrm{cm}^{-3}$ fell to $144 \mathrm{mg} \cdot \mathrm{cm}^{-3}$ after 12 months of treatment, and $145 \mathrm{mg} \cdot \mathrm{cm}^{-3}$ after 24 months of treatment (table 2). When the treatment difference between FP and BDP was compared, there were statistically significant differences in favour of FP at both 12 and 24 months $(p=0.006$ and $p=0.004)$. Similar results were observed with DE-QCT for which there was a statistically significant difference between FP and BDP at 24 months $(\mathrm{p}=0.033)$ (table 2), indicating that the changes observed were due to changes in bone mineral and not due to changes in marrow fat.

Mean baseline QCT values in control group A (lowdose inhaled corticosteroids) were of a similar magnitide to the FP and BDP groups, and fell slightly over the 2 yrs (table 2). The oral corticosteroid patients (control group B) had considerably lower mean QCT values at baseline and after 2 yrs than either the randomized high-dose treatment groups (FP and BDP) or the low dose inhaled corticosteroid group (control group A). In the healthy volunteers (control group $\mathrm{C}$ ), the mean BMD values at baseline and throughout the study were higher than for the other groups.

Dual energy X-ray absorptiometry of the spine, femoral neck and whole body. In both the FP and BDP groups, mean BMD values for spine and femoral neck were essentially unchanged at $0,6,12$ and 24 months. From the summarized data (table 3 ) a slight reduction in whole body mean BMD can be observed in both the FP group and the healthy volunteers (control group C). In the open control groups, the DXA results generally reflected those seen with QCT, with the oral corticosteroid group showing lower BMD values and the healthy volunteers higher BMD values than the patients treated with inhaled corticosteroids (table 3 ).

SPA of forearm. Mean proximal BMD increased slightly over baseline at 6,12 and 24 months in both the FP and BDP groups but there were no significant differences (table 4). In the open control groups, the findings again reflected those seen with QCT.

\section{Biochemical markers}

Bone formation. Figure 2 shows the median 3 month serum OC values in each of the groups. No statistically significant differences in treatment effects between FP and BDP were found at either 12 or 24 months. Throughout the study, median OC values were lowest (and

Table 2. - Quantitative computed tomography (QCT) analysis of vertebral trabecular bone mineral density

\begin{tabular}{|c|c|c|c|c|c|c|c|c|c|c|c|c|c|c|c|c|}
\hline \multirow{3}{*}{ Month } & & & & & & & & \multicolumn{9}{|c|}{ Open control groups } \\
\hline & \multicolumn{3}{|c|}{$\begin{array}{c}\text { FP } \\
1000 \\
\mu \mathrm{g} \cdot \text { day }^{-1}\end{array}$} & \multicolumn{3}{|c|}{$\begin{array}{c}\text { BDP } \\
2000 \\
\mu \mathrm{g} \cdot \text { day }^{-1}\end{array}$} & \multirow{2}{*}{$\begin{array}{l}\text { Treatment } \\
\text { difference } \\
\text { FP-BDP }\end{array}$} & \multicolumn{3}{|c|}{$\begin{array}{c}\text { A } \\
\text { Low-dose } \\
\text { inhaled CS }\end{array}$} & \multicolumn{3}{|c|}{$\begin{array}{c}\text { B } \\
\text { Oral CS }\end{array}$} & \multicolumn{3}{|c|}{$\begin{array}{c}\text { C } \\
\text { Healthy } \\
\text { volunteers }\end{array}$} \\
\hline & $\mathrm{n}$ & Mean & SD & $\mathrm{n}$ & Mean & $\mathrm{SD}$ & & $\mathrm{n}$ & Mean & $\mathrm{SD}$ & $\mathrm{n}$ & Mean & $\mathrm{SD}$ & $\mathrm{n}$ & Mean & SD \\
\hline \multicolumn{17}{|c|}{ Single energy QCT } \\
\hline 0 & 16 & 152 & 28.0 & 14 & 152 & 16.0 & - & 14 & 152 & 21.2 & 8 & 99 & 24.2 & 7 & 169 & 18.2 \\
\hline 12 & 15 & 154 & 29.2 & 9 & 144 & 19.5 & $\mathrm{p}=0.0006^{*}$ & 8 & 144 & 23.2 & 8 & 91 & 24.6 & 7 & 164 & 17.6 \\
\hline 24 & 15 & 153 & 26.8 & 9 & 145 & 19.6 & $\mathrm{p}=0.004^{+}$ & 7 & 143 & 25.2 & 8 & 91 & 22.1 & 7 & 162 & 18.2 \\
\hline \multicolumn{17}{|c|}{ Dual energy QCT } \\
\hline 0 & 16 & 154 & 24.4 & 14 & 153 & 15.7 & - & 14 & 153 & 17.2 & 8 & 103 & 19.3 & 7 & 167 & 17.6 \\
\hline 12 & 15 & 155 & 30.6 & 9 & 148 & 21.3 & NS & 8 & 147 & 21.5 & 8 & 96 & 22.8 & 7 & 165 & 20.8 \\
\hline 24 & 15 & 161 & 24.2 & 9 & 148 & 24.6 & $\mathrm{p}=0.033^{\#}$ & 7 & 141 & 25.2 & 8 & 100 & 20.2 & 7 & 165 & 30.5 \\
\hline
\end{tabular}

Bone mineral density values given as $\mathrm{mg} \cdot \mathrm{cm}^{-3}$. FP: fluticasone propionate; BDP: beclomethasone dipropionate; CS: corticosteroids. Open control groups A-C are defined in table 1. *: Adjusted mean difference FP and BDP $=9 \mathrm{mg} \cdot \mathrm{cm}^{-3}(95 \%$ confidence limits (CI) 3$16) ;^{+}:$Adjusted mean difference between FP and BDP $=9 \mathrm{mg} \cdot \mathrm{cm}^{-3}$ (95\% CI 3-14); ${ }^{\#}$ : Adjusted mean difference between FP and BDP $=14 \mathrm{mg} \cdot \mathrm{cm}^{-3}(95 \%$ CI $1-26)$. 
Table 3. - Dual-energy X-ray absorptiometry analysis of spine, femoral neck, and whole body bone mineral density

\begin{tabular}{|c|c|c|c|c|c|c|c|c|c|c|c|c|c|c|c|c|}
\hline \multirow{3}{*}{ Month } & & & & & & & \multirow{3}{*}{$\begin{array}{l}\text { Treatment } \\
\text { difference } \\
\text { FP-BDP }\end{array}$} & \multicolumn{9}{|c|}{ Open control groups } \\
\hline & \multicolumn{3}{|c|}{$\begin{array}{c}\text { FP } \\
1000 \\
\mu \mathrm{g} \cdot \text { day }^{-1}\end{array}$} & \multicolumn{3}{|c|}{$\begin{array}{c}\text { BDP } \\
2000 \\
\mu \mathrm{g} \cdot \text { day }^{-1}\end{array}$} & & \multicolumn{3}{|c|}{$\begin{array}{c}\text { A } \\
\text { Low-dose } \\
\text { inhaled CS }\end{array}$} & \multicolumn{3}{|c|}{$\begin{array}{c}\text { B } \\
\text { Oral CS }\end{array}$} & \multicolumn{3}{|c|}{$\begin{array}{c}\text { C } \\
\text { Healthy } \\
\text { volunteers }\end{array}$} \\
\hline & $\mathrm{n}$ & Mean & SD & $\mathrm{n}$ & Mean & $\mathrm{SD}$ & & $\mathrm{n}$ & Mean & $\mathrm{SD}$ & $\mathrm{n}$ & Mean & SD & $\mathrm{n}$ & Mean & SD \\
\hline \multicolumn{17}{|l|}{ Spine } \\
\hline 0 & 16 & 1.213 & 0.145 & 14 & 1.201 & 0.163 & - & 14 & 1.241 & 0.126 & 8 & 0.904 & 0.145 & 7 & 1.329 & 0.122 \\
\hline 6 & 15 & 1.213 & 0.155 & 8 & 1.219 & 0.193 & - & 10 & 1.238 & 0.113 & 8 & 0.897 & 0.132 & 5 & 1.341 & 0.118 \\
\hline 12 & 15 & 1.210 & 0.161 & 9 & 1.243 & 0.188 & NS & 8 & 1.218 & 0.090 & 8 & 0.885 & 0.143 & 7 & 1.308 & 0.137 \\
\hline 24 & 15 & 1.211 & 0.165 & 9 & 1.221 & 0.182 & NS & 8 & 1.214 & 0.103 & 8 & 0.889 & 0.110 & 7 & 1.291 & 0.137 \\
\hline \multicolumn{17}{|c|}{ Femoral neck } \\
\hline 0 & 16 & 1.014 & 0.155 & 14 & 1.021 & 0.139 & - & 14 & 1.069 & 0.094 & 8 & 0.825 & 0.149 & 7 & 1.119 & 0.106 \\
\hline 6 & 15 & 1.012 & 0.171 & 8 & 1.023 & 0.158 & - & 10 & 1.064 & 0.104 & 8 & 0.829 & 0.110 & 5 & & 0.128 \\
\hline 12 & 15 & 1.007 & 0.131 & 9 & 1.026 & 0.156 & NS & 8 & 1.075 & 0.105 & 8 & 0.804 & 0.115 & 7 & 1.109 & 0.107 \\
\hline 24 & 15 & 1.010 & 0.141 & 9 & 1.013 & 0.162 & NS & 8 & 1.085 & 0.100 & 8 & 0.797 & 0.111 & 7 & 1.084 & 0.106 \\
\hline \multicolumn{17}{|c|}{ Whole body } \\
\hline 0 & 10 & 1.229 & 0.134 & 8 & 1.185 & 0.098 & - & 10 & 1.255 & 0.078 & 7 & 1.082 & 0.069 & 2 & 1.343 & 0.177 \\
\hline 6 & 15 & 1.209 & 0.105 & 8 & 1.204 & 0.086 & - & 10 & 1.277 & 0.050 & 8 & 1.088 & 0.097 & 5 & & 0.106 \\
\hline 12 & 15 & 1.203 & 0.110 & 9 & 1.209 & 0.085 & NS & 8 & 1.265 & 0.065 & 8 & 1.089 & 0.087 & 7 & 1.280 & 0.100 \\
\hline 24 & 15 & 1.203 & 0.098 & 9 & 1.195 & 0.086 & NS & 8 & 1.256 & 0.064 & 8 & 1.096 & 0.075 & 7 & 1.263 & 0.087 \\
\hline
\end{tabular}

Bone mineral density values given as $\mathrm{g} \cdot \mathrm{cm}^{-2}$. FP: fluticasone dipropionate; BDP: beclomethasone dipropionate; CS: corticosteroid. Open control groups $\mathrm{A}-\mathrm{C}$ are defined in table 1 .

below the normal range) in control group B patients (oral corticosteroids) and highest in the healthy volunteers (control group C). For serum P1CP, BAP and parathyroid hormone, there were no obvious differences between any of the groups at baseline or during the 2-yr treatment period, and no statistically significant difference in treatment effects between FP and BDP at either 12 or 24 months.

Bone resorption. The urinary bone marker results were highly variable and showed no consistent pattern across the groups (fig. 2). There were no statistically significant differences in treatment effects between FP and BDP at either 12 or 24 months for either of these parameters or for urinary calcium-creatinine ratio.

\section{Clinic assessments}

Baseline lung function measurements are summarized in table 1 and clinic peak expiratory flow rate measurements during the study in table 5. The adverse events profile and overall incidence of adverse events reported during the 2-yr treatment period were similar in both the FP and BDP groups, with asthma and asthma-related events reported the most (in $65 \%$ of patients in the FP group and $75 \%$ in the BDP group), followed by respiratory infections. In the FP group, 11 patients $(65 \%$ of those randomized) received a short course of oral corticosteroids for an asthma exacerbation on $\geq 1$ occasions during the treatment period compared with six patients (38\% of those randomized) in the BDP group. Geometric mean serum cortisols (fig. 2) remained above the lower limit of the normal range throughout the study in both the FP and BDP groups and there were no statistically significant treatment differences between FP and BDP after 12 or 24 months.

\section{Discussion}

Guidelines for the management of asthma emphasize that treatment should be aimed at the basic pathophysiology of asthma, i.e. airway inflammation [14]. With such an emphasis on inhaled corticosteroids for optimal control of symptoms, physicians have sought clarification on the issue of their long term effects on bone density. This 2-yr prospective study of asthmatic patients in a specific agerange with expected peak bone density, suggests that high dose inhaled corticosteroids have little or no effects on bone density.

In the present study, a comparably efficacious dosage regime of FP and BDP $\left(1,000 \mu \mathrm{g} \cdot \mathrm{day}^{-1} \mathrm{FP}\right.$ versus 2,000 $\left.\mu \mathrm{g} \cdot \mathrm{day}^{-1} \mathrm{BDP}\right)$ was chosen rather than a dose based on potential bioavailability. A 2:1 efficacy ratio has been determined by previous clinical studies [15]. Therefore, dosages of comparable clinical efficacy were used to control for the potential of excess rescue oral corticosteroid exposure. This anticipated excess exposure to oral corticosteroids would have confounded the longitudinal follow-up of the bone density data.

The propensity of patients with moderately high requirements for inhaled corticosteroids to need oral corticosteroid rescue therapy is illustrated by the number of withdrawals from the BDP group. Almost half of the withdrawals in the BDP group were due to asthma exacerbations requiring oral corticosteroid rescue therapy. Despite a trend for lower peak flows in the FP group compared to the BDP group the 2:1 clinical efficacy ratio was emphasized by the control of symptoms. The dose-response curve for airway inflammation does not mirror the dose-response curve for symptom control [16].

A number of short-term studies have evaluated the potential effects of inhaled corticosteroids and biochemical markers of bone turnover. Two studies on normal individuals have looked at the effects of inhaled BDP without spacer devices on serum OC, a marker of bone formation 
Table 4. - Single photon absorptiometry analysis of forearm bone mineral density and bone mineral content

\begin{tabular}{|c|c|c|c|c|c|c|c|c|c|c|c|c|c|c|c|c|}
\hline \multirow{3}{*}{ Month } & & & & & & & \multirow{3}{*}{$\begin{array}{l}\text { Treatment } \\
\text { difference } \\
\text { FP-BDP }\end{array}$} & \multicolumn{9}{|c|}{ Open control groups } \\
\hline & \multicolumn{3}{|c|}{$\begin{array}{c}\text { FP } \\
1000 \\
\mu \mathrm{g} \cdot \text { day }^{-1}\end{array}$} & \multicolumn{3}{|c|}{$\begin{array}{c}\text { BDP } \\
2000 \\
\mu \mathrm{g} \cdot \text { day }^{-1}\end{array}$} & & \multicolumn{3}{|c|}{$\begin{array}{c}\text { A } \\
\text { Low-dose } \\
\text { inhaled CS }\end{array}$} & \multicolumn{3}{|c|}{$\begin{array}{c}\text { B } \\
\text { Oral CS }\end{array}$} & \multicolumn{3}{|c|}{$\begin{array}{c}\text { C } \\
\text { Healthy } \\
\text { volunteers }\end{array}$} \\
\hline & $\mathrm{n}$ & Mean & SD & $\mathrm{n}$ & Mean & SD & & $\mathrm{n}$ & Mean & SD & $\mathrm{n}$ & Mean & SD & $\mathrm{n}$ & Mean & SD \\
\hline \multicolumn{17}{|c|}{ Distal Forearm BMC } \\
\hline 0 & 16 & 1.516 & 0.395 & 14 & 1.564 & 0.378 & - & 14 & 1.601 & 0.359 & 8 & 1.438 & 0.439 & 7 & 1.664 & 0.359 \\
\hline 6 & 15 & 1.530 & 0.431 & 8 & 1.672 & 0.430 & - & 10 & 1.719 & 0.384 & 8 & 1.439 & 0.424 & 5 & 1.800 & 0.398 \\
\hline 12 & 15 & 1.526 & 0.409 & 9 & 1.655 & 0.389 & NS & 8 & 1.820 & 0.372 & 8 & 1.451 & 0.420 & 7 & 1.687 & 0.330 \\
\hline 24 & 15 & 1.526 & 0.425 & 9 & 1.665 & 0.387 & NS & 7 & 1.805 & 0.378 & 8 & 1.419 & 0.408 & 7 & 1.707 & 0.330 \\
\hline \multicolumn{17}{|c|}{ Distal Forearm BMD } \\
\hline 0 & 16 & 0.373 & 0.073 & 14 & 0.395 & 0.065 & - & 14 & 0.396 & 0.079 & 8 & 0.345 & 0.075 & 7 & 0.411 & 0.083 \\
\hline 6 & 15 & 0.387 & 0.086 & 8 & 0.404 & 0.075 & - & 10 & 0.408 & 0.062 & 8 & 0.338 & 0.069 & 5 & 0.434 & 0.067 \\
\hline 12 & 15 & 0.382 & 0.073 & 9 & 0.413 & 0.073 & NS & 8 & 0.436 & 0.071 & 8 & 0.338 & 0.071 & 7 & 0.420 & 0.093 \\
\hline 24 & 15 & 0.373 & 0.079 & 9 & 0.399 & 0.060 & NS & 7 & 0.416 & 0.058 & 8 & 0.327 & 0.072 & 7 & 0.429 & 0.074 \\
\hline \multicolumn{17}{|c|}{ Proximal Forearı } \\
\hline 0 & 16 & 1.469 & 0.369 & 14 & 1.525 & 0.3 & - & 14 & 1.531 & 0.309 & 8 & 1.507 & 0.357 & 7 & 1.553 & 0.311 \\
\hline 6 & 15 & 1.485 & 0.394 & 8 & 1.606 & 0.373 & - & 10 & 1.585 & 0.346 & 8 & 1.505 & 0.367 & 5 & 1.666 & 0.317 \\
\hline 12 & 15 & 1.498 & 0.391 & 9 & 1.624 & 0.355 & $\mathrm{p}=0.032 *$ & 8 & 1.654 & 0.328 & 8 & 1.507 & 0.370 & 7 & 1.564 & 0.299 \\
\hline 24 & 15 & 1.486 & 0.395 & 9 & 1.630 & 0.351 & NS & 7 & 1.647 & 0.350 & 8 & 1.497 & 0.358 & 7 & 1.569 & 0.319 \\
\hline \multicolumn{17}{|c|}{ Proximal Fore } \\
\hline 0 & 16 & 0.512 & 0.089 & 14 & 0.513 & 0.066 & - & 14 & 0.525 & 0.072 & 8 & 0.500 & 0.064 & 7 & 0.540 & 0.080 \\
\hline 6 & 15 & 0.519 & 0.094 & 8 & 0.532 & 0.074 & - & 10 & 0.533 & 0.065 & 8 & 0.493 & 0.064 & 5 & 0.574 & 0.079 \\
\hline 12 & 15 & 0.522 & 0.084 & 9 & 0.538 & 0.071 & NS & 8 & 0.557 & 0.057 & 8 & 0.495 & 0.068 & 7 & 0.549 & 0.083 \\
\hline 24 & 15 & 1.203 & 0.098 & 9 & 1.195 & 0.086 & NS & 8 & 1.256 & 0.064 & 8 & 1.096 & 0.075 & 7 & 1.263 & 0.087 \\
\hline
\end{tabular}

BMC: bone mineral content $\left(\mathrm{g} \cdot \mathrm{cm}^{-1}\right)$; BMD: bone mineral density $\left(\mathrm{g} \cdot \mathrm{cm}^{-2}\right)$; FP: fluticasone dipropionate; BDP: beclomethasone diprionate; $\mathrm{CS}$ : corticosteroids. Open control groups $\mathrm{A}-\mathrm{C}$ are defined in table 1 . *: Treatment difference between FD and BDP=0.029 $\mathrm{g} \cdot \mathrm{cm}^{-1}(95 \%$ confidence limits $0.003-0.055)$.

$[2,3]$. These suggest that $1,500-2,000 \mu \mathrm{g} \cdot \mathrm{day}^{-1}$ of BDP has sufficient systemic absorption to suppress OC while the use of spacer devices may occasionally but not always negate this effect $[17,18]$. The present study did not demonstrate the suppression of markers of bone turnover in asthmatic patients using a spacer device who were already taking high-dose inhaled steroids, an observation also reported in other studies of asthmatic patients. However, pro-collagen type 1 aminoterminal propeptide (P1NP), a sensitive marker of bone formation, was not studied [19]. Although the interpretation of changes in markers of bone formation and breakdown in short-term studies can be difficult, such studies do raise important questions, especially as to whether short-term studies in bone turnover have any relevance to the long-term status of bone density. In addition, such studies do not address the long-term influence of high-dose inhaled steroids on the bone structure itself. Studies using radiological techniques for measuring bone density are most likely to give accurate insights into these questions.

Using bone densitometry, several retrospective studies have highlighted a potential for a reduction in bone density in patients with moderate to severe chronic persistent asthma $[5,6,20]$. These cross-sectional studies suggest that the patients requiring high-dose inhaled corticosteroids and intermittent oral prednisolone have reduced bone density in comparison to control subjects [20]. However, these studies relied on historical data for estimating previous oral corticosteroid exposure. The present study corrects for the problem of oral corticosteroid exposure. In the randomized treatment groups, prior oral corticosteroid exposure was comparable. Data regarding exposure to oral corticosteroids were carefully collected and were comparable between the two randomized treatment groups.

In a prospective study, HerRala et al. [21] evaluated bone density using DXA in steroid-naive females who were started on $1,000 \mu \mathrm{g} \cdot$ day $^{-1}$ inhaled BDP via a spacer device. No change in bone density was observed over $1 \mathrm{yr}$ when compared with untreated controls. However, a minimum of 2 yrs follow-up is required to exclude an affect of inhaled therapy on the measurement of bone density [22]. In the present study, serial bone density measurements using a number of techniques (SPA, DXA, and QCT) were evaluated. These results suggest that single energy and dual energy QCT may be the most sensitive techniques for detecting a change within trabecular bone in longitudinal studies, in contrast to the more widely available technique of DXA and SPA. However, a precision range of $2.5 \%$ for SE-QCT must be acknowledged. Nevertheless, studies like that of Herralla et al. [21] which report normal findings with SPA and DXA must be interpreted with caution.

The present findings suggest that inhaled corticosteroids may have the potential to reduce bone density, a change which was not seen with FP. Although there was a change in bone density with BDP relative to FP, mean bone density in the BDP group remained within the normal range. However, with the small change in bone density with BDP over 2 yrs it could be speculated that with continuing exposure over many years, a clinically important change might become evident [23]. This has to be judged against the use of rescue oral corticosteroid therapy. The control patients receiving maintenance oral corticosteroids had severely depressed bone density prior to the expected physiological decline with age (fig. 1). 

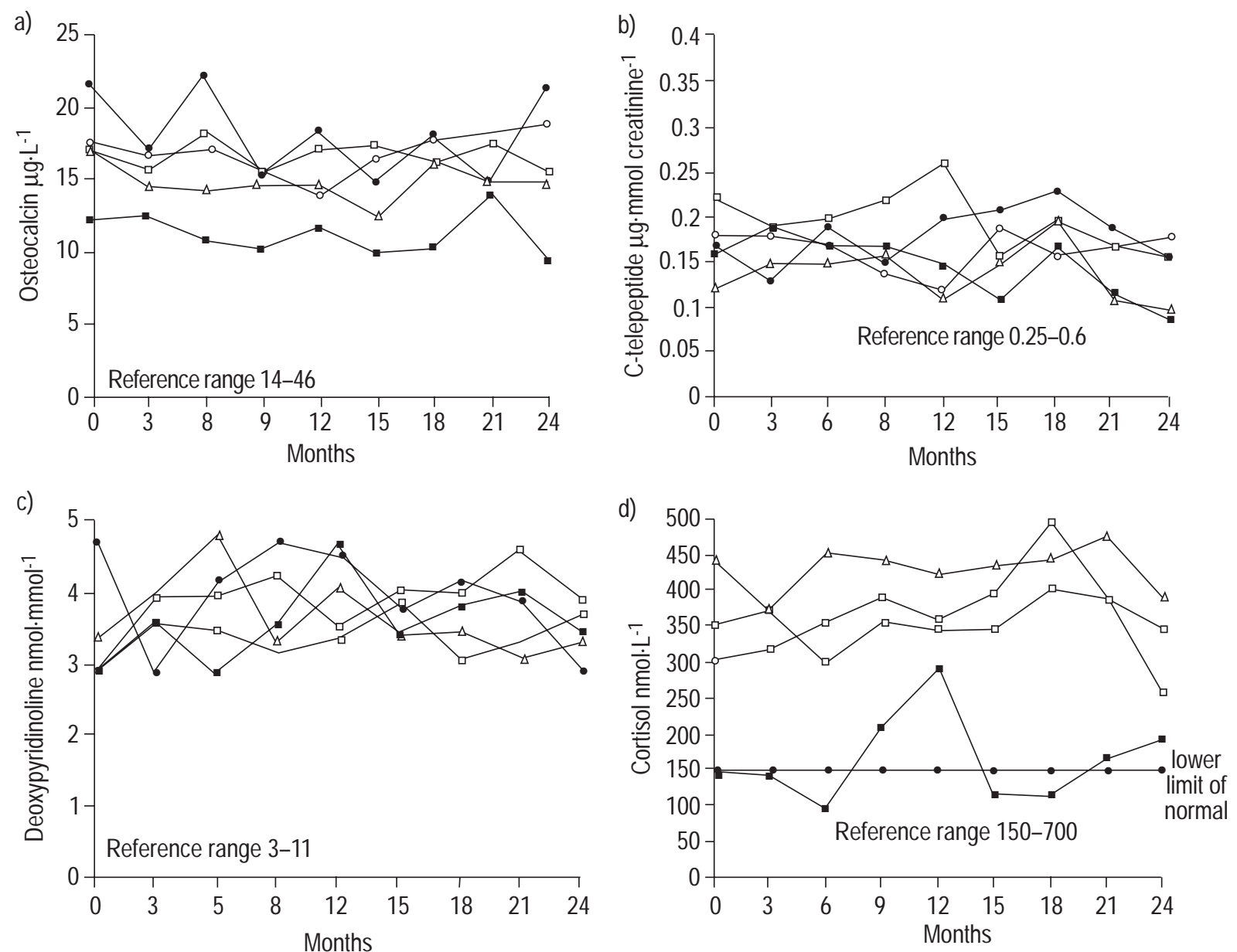

Fig. 2. - Longitudinal change over 24 months for markers of bone turnover, a) median values for osteocalcin, b) median values of urinary C-telopeptide type 1 collagen, c) median values of urinary free deoxypyridinoline, d) mean serum cortisols. $\bigcirc$ : fluticasone dipropionate $1,000 \mu \mathrm{g} \cdot$ day ${ }^{-1}$; $\square$ : beclomethasone dipropionate $2,000 \mu \mathrm{g} \cdot \mathrm{day}^{-1} ; \triangle$ : low-dose inhaled corticosteroids $\left(\leq 400 \mu \mathrm{g} \cdot\right.$ day $^{-1}$ ) (control group A); $\mathbf{\square}$ : maintenance oral corticosteroids $\left(\geq 10 \mu \mathrm{g} \cdot \mathrm{day}^{-1}\right)$ (control group B); $\bullet$ : healthy volunteers (control group $\mathrm{C}$ ).

At study entry, the control group receiving maintenance oral steroids had abnormally reduced bone density as assessed by all parameters. It is interesting that the bone density in those patients receiving low-dose inhaled steroids $\left(<400 \mu \mathrm{g} \cdot\right.$ day $\left.^{-1}\right)$ was comparable to those patients receiving high-dose inhaled steroids. Low doses of inhaled corticosteroids are generally accepted as having negligible bioavailability and therefore little or no affect on the bone density of adults. These finding mirrors those of BOULET et al. [24] who showed no significant difference in bone density between patients who had used high-dose inhaled steroids $\left(>1,000 \mu \mathrm{g} \cdot \mathrm{day}^{-1}\right)$ and those who received low dose inhaled steroids $\left(<500 \mu \mathrm{g} \cdot \mathrm{day}^{-1}\right)$. However, the present data and the data of Boulet et al. [24] are in contrast to those of HANANIA et al. [25], who reported that North American patients receiving a mean dose of 1,300 $\mu \mathrm{g} \cdot \mathrm{day}^{-1}$ inhaled steroid had reduced bone density. A reconciliation of these different observations implies that

Table 5. - Clinic peak expiratory flow measurements

\begin{tabular}{|c|c|c|c|c|c|c|c|c|c|c|c|c|}
\hline \multirow{3}{*}{ Month } & & & & & & & \multicolumn{6}{|c|}{ Open control groups } \\
\hline & \multicolumn{3}{|c|}{$\begin{array}{c}\text { FP } \\
1000 \mu \mathrm{g} \cdot \text { day }^{-1}\end{array}$} & \multicolumn{3}{|c|}{$\begin{array}{c}\text { BDP } \\
2000 \mu \mathrm{g} \cdot \text { day }^{-1}\end{array}$} & \multicolumn{3}{|c|}{$\begin{array}{c}\text { A } \\
\text { Low-dose } \\
\text { inhaled CS }\end{array}$} & \multicolumn{3}{|c|}{$\begin{array}{c}\text { B } \\
\text { Oral CS }\end{array}$} \\
\hline & $\mathrm{n}$ & Mean & SD & $\mathrm{n}$ & Mean & SD & $\mathrm{n}$ & Mean & SD & $\mathrm{n}$ & Mean & SD \\
\hline 0 & 16 & 429 & 102.5 & 16 & 459 & 135.9 & 16 & 489 & 109.4 & 7 & 287 & 134.6 \\
\hline 6 & 16 & 455 & 107.2 & 9 & 485 & 140.4 & 11 & 529 & 92.4 & 8 & 238 & 108.5 \\
\hline 12 & 15 & 444 & 93.5 & 9 & 499 & 121.4 & 9 & 528 & 98.6 & 8 & 248 & 103.8 \\
\hline 18 & 14 & 430 & 102.5 & 9 & 501 & 120.8 & 6 & 523 & 94.4 & 6 & 260 & 75.4 \\
\hline 24 & 15 & 431 & 105.8 & 9 & 513 & 110.2 & 7 & 526 & 135.7 & 7 & 297 & 125.3 \\
\hline
\end{tabular}

Values are given as $\mathrm{L} \cdot \mathrm{min}^{-1}$. FP: fluticasone dipropionate; BDP: beclomethasone dipropionate; CS: corticosteroids. Open control groups $\mathrm{A}$ and $\mathrm{B}$ are defined in table 1. 
factors common to all asthmatic patients are potentially more important in determining bone density than individual inhaled or oral drug dose. The severity of asthma symptoms and their influence on exercise is a key factor that may explain the disparity in the findings between different dosages used in different studies. Exercise is one variable that was not controlled for in the present study. In patients with postmenopausal osteoporosis, exercise programmes have an independent positive impact on bone density and this is likely to be very important in patients with asthma [26]. In premenopausal women, high impact exercise independently increases bone density [27].

Although the data obtained from the control groups in the present study provide an interesting comparison to the randomized groups, they were not subjected to statistical analysis as they were open nonrandomized groups. The statistical analysis focused on the treatment differences between the randomized double-blind treatment groups (BDP and FP). Such between-group analysis allows a more accurate assessment of the influence of the treatment of the measured variables [28]. This is in contrast to many studies which evaluate within-group changes in bone density (bone density at baseline versus bone density at completion). Within-group analysis has the propensity to exaggerate changes that occur as a result of nontreatment variables such as exercise or diet.

The relatively small number of patients in each treatment group must be acknowledged, which is a reflection of the age group studied. In order to correct for the physiological decline in bone density that occurs after the age of $40 \mathrm{yrs}$ in females and $50 \mathrm{yrs}$ in males, only patients of expected peak bone mass were studied. A wider age-range would have facilitated recruitment but may have confounded the data. This further emphasizes the difficulty in controlling for all potential factors including genetic factors and exercise that may influence bone density [29].

Studies of bone density measurements using dualenergy X-ray absorptiometry have further implied that patients receiving high-dose inhaled corticosteroids have reduced bone density, but this data is confounded by the difficulty in the accurate assessment of exposure to oral corticosteroids. The present study using sensitive imaging techniques for detecting changes in bone density over 2 yrs suggests that long-term changes in bone density in patients on high-dose inhaled corticosteroids are minimal. Those patients receiving maintenance oral corticosteroids have abnormally reduced bone density. Therefore, for the optimal control of asthma symptoms, titrating inhaled corticosteroids and consequently reducing the exposure to oral corticosteroids and facilitating exercise are probably the most effective strategies to prevent changes in bone density in asthmatic patients.

Acknowledgements. The authors wish to thank K. Carroll, P. Barber, T. Pickering and A. Hilton of the North-West Lung Centre, S. Hanley, North Manchester General Hospital and S. Owen, Warrington General Hospital, all of whom contributed subjects to the study. Bone densitometry was performed by C. Alsop and I. Hodgkinson.

\section{References}

1. Geddes DM. Inhaled coticosteroids: benefits and risks. Thorax 1992; 47: 404-407.
2. Teelucksingh S, Padfield PL, Tibi L, Gough KJ, Holt PR. Inhaled corticosteroids, bone formation and osteocalcin. Lancet 1991; 338: 60-61.

3. Pouw EP, Prummel MF, Ossting H, Roos Cm, Endert E. Beclomethasone inhalation decreases serum osteocalcin concentrations. Br Med J 1991; 302: 627-628.

4. Bootsma GP, Dekhuijzen PNR, Festen J, Mulder PGH, Swinkels LMJW, van Herwaarden CLA. Fluticasone proprionate does not influence bone metabolism in contrast to becolmethasone diproprionate. Am J Respir Crit Care Med 1996; 153: 924-930.

5. Packe GE, Douglas JG, McDonald AF, Robins SP, Reid DM. Bone density in asthmatics taking high dose inhaled beclomethasone dipropionate. Thorax 1992; 47: 415418.

6. Packe GE, Robb O, Robbins SP, Reid SP, Douglas JG. Bone density in asthmatic patients taking inhaled corticosteroids: comparison of budesonide and beclomethasone diproprionate. J Royal College Phys (London) 1996; 30: $128-132$.

7. Adams JE, Adams PH. The measurement of spinal bone mass by quantitative computed tomography: assessment of precision and different calibration phantoms. $\mathrm{Br} J$ Radiol 1988; 61: 724.

8. Whitehouse RW, Adams JE, Bancroft K, VaughanWilliams CA, Elstein M. The effects of nafarelin and danazol on vertebral trabecular bone mass in patients with endometriosis. Clin Endocrinol 1990; 33: 365-373.

9. Cann CE, Genant HK. Precise measurement of vertebral mineral content using computed tomography. J Comput Assist Tomogr 1980; 4: 493-500.

10. Adams JE, Chen SZ, Adams PH, Isherwood I. Measurement of trabecular bone mineral by dual energy computed tomography. J Comput Assist Tomogr 1982; 6: 601-607.

11. Cullum ID, Ell PJ, Ryder JP. X-ray dual-photon absorptiometry: a new method for the measurement of bone density. Br J Radiol 1989; 62: 587-592.

12. Wahner HW, Riggs BL, Beabout JW. Diagnosis of osteporosis: usefulness of photon absorptiometry at the radius. J Nucl Med 1977; 18: 432-437.

13. Rosalki SB, Foo AY. Two new methods for separating and quantifying bone and liver alkaline phosphatase isoenzymes in plasma. Clin Chem 1984; 30: 1182-1186.

14. The British Guidelines on Asthma Management: 1995 Review and Position Statement. Thorax 1997; 52: Suppl. 1, S1-S21.

15. Ayers JG, Bateman ED, Lundback B, Harris TAJ. High dose fluticasone proprionate $1 \mathrm{mg}$ daily, versus fluticasone, $2 \mathrm{mg}$ daily, or budesonide, $1.6 \mathrm{mg}$ daily, in patients with chronic severe asthma. Eur Respir J 1995: 8; 579-586.

16. Sont JK, Han J, van Krieken JM, et al. Relationship between the inflammatory infiltrate in bronchial biopsy specimens and clinical severity of asthma in patients treated with inhaled steroids. Thorax 1996; 51: 496-502.

17. Meeran K, Burrin JM, Noonan KA, Price CP, Ind PW. A large volume spacer significantly reduces the effect of inhaled steroids on bone formation. Postgrad Med $J$ 1995; 71: 156-159.

18. Puolijoki H, Liippo K, Herrala J, Salmi J, Tala E. Inhaled beclomethasone decreases serum osteocalcin in postmenopausal asthmatic women. Bone 1992; 13: 285-288.

19. Puolijoki H, Risteli J, Herrala J, Risteli L, Lippo K. Effect of inhaled beclomethasone on serum markers of collagen metabolism in postmenopausal asthmatic women. Respiratory Med 1996; 90: 339-342.

20. Ip M, Lam K, Yam L, Kung A, Ng M. Decreased bone 
mineral density in premenopausal asthma patients receiving long-term inhaled steroids. Chest 1994; 105: 17221727.

21. Herrala J, Puolijoki H, Imprivaara O, Lilppo K, Tala E, Nieminen MM. Bone mineral density in asthmatic women on high-dose inhaled beclomethasone dipropionate. Bone 1994; 15: 621-623.

22. Heaney RP. Interpreting trials of bone active agents. Am J Med 1995; 98: 329-330.

23. Wisniewski AF, Lewis SA, Green DJ, Maslanka W, Burrell H, Tattersfield AE. Cross sectional investigation of the effects of inhaled cortiscosteroids on bone density and bone metabolism in patients with asthma. Thorax 1997; 52: 853-860.

24. Boulet LP, Giguére MC, Milot J, Brown J. Effects of long-term use of high dose inhaled steroids on bone density and calcium metabolism. J Allergy Clin Immunol 1994; 94: 796-803.
25. Hanania NA, Chapman KR, Sturtridge WC, Szalai JP, Kesten S. Dose-related decrease in bone density among asthmatic patients treated with inhaled corticosteroids. $J$ Allergy Clin Immunol 1995; 96: 571-579.

26. Nelson ME, Fiatarone MA, Morganti CM, Trice I, Greenberg RA, Evans WJ. Effects of high-intensity strength training on multiple risk factors for osteoporotic fractures: a randomised controlled trial. JAMA 1994; 272: 1909-1914.

27. Heinonen A, Kannus P, Sievanen H, et al. Randomized controlled trial of high-impact exercise on selected risk factors for osteoporotic fractures. Lancet 1996; 348: 134137.

28. Campbell MJ, Machin D. Medical Statistics: a common sense approach. 2nd Edn. John Wiley \& Sons Inc, Chichester, 1995.

29. Greenfield EM, Goldberg VM. Genetic determination of bone density. Lancet 1997; 350: 1263-1264. 